\title{
Mesenchymal Bone Marrow-derived Stem Cells Transplantation in Patients with HCV Related Liver Cirrhosis
}

\author{
Sviatlana P. Lukashyk ${ }^{1}$, Vladimir M. Tsyrkunov*2, Yanina I. Isaykina ${ }^{3}$, Oksana N. Romanova ${ }^{3}$, \\ Artur T. Shymanskiy ${ }^{3}$, Olga V. Aleynikova ${ }^{3}$ and Rimma I. Kravchuk ${ }^{4}$ \\ ${ }^{1}$ Department of Infection Diseases, The Belarusian State Medical University, Minsk, Republic of Belarus; ${ }^{2}$ Department of Infection \\ Diseases, The Grodno State Medical University, Grodno, Republic of Belarus; ${ }^{3}$ Cell biotechnology and cytotherapy laboratory, The \\ Republican Research and Practical Center of Pediatric Oncology and Hematology, Minsk, Republic of Belarus; ${ }^{4}$ Central Scientific \\ Research Laboratory, The Grodno State Medical University, Grodno, Republic of Belarus
}

\begin{abstract}
Background and Aims: To evaluate the effect of intraparenchymal transplantation of mesenchymal bone marrowderived stem cells (BMSCs) in patients with hepatitis $C$ virus (HCV)-related liver cirrhosis (LC). Methods: Mononuclear cells were isolated from patient bone marrow and were passaged several times in vitro in order to reach the required volume. Attributes of the BMSCs were evaluated by the presence of the surface markers CD105+, CD90+, and CD73+. Cells from each passage were evaluated for sterility, and they were transplanted intraparenchymally into liver tissue. Clinical and laboratory data were evaluated and morphological studies of liver biopsy were performed prior to and 6 months after transplantation. Results: On clinical evaluation, the general state of these patients was improved at 1 month following transplantation of BMSCs. At 1 and 6 months post-transplantation, jaundice was absent in four $(67 \%)$ patients. After 6 months, functional hepatic indices were improved, i.e. decrease of ALT and AST activity and bilirubin level. However, these decreases were not statistically different $(P>0.05)$. Expression of CD34 and $\alpha$-SMA in liver biopsy samples were decreased at 6 months after transplantation, consistent with structural improvements in mitochondria and nuclear compartments. Conclusions: Intraparenchymal transplantation of autologous BMSCs improved the functional condition of the liver, stimulated reparative processes in hepatocytes, and decreased extracellular matrix protein (EMP) count in hepatic tissues of patients with LC. It was well
\end{abstract}

Keywords: Liver cirrhosis; Mesenchymal bone marrow stem cells; Transplantation therapy.

Abbreviations: ALT, alanine aminotransferase; AST, aspartate aminotransferase; BMSCs, bone marrow-derived mesenchymal stem cells; ECM, extracellular matrix; EM, electronic microscopic; EMP, extracellular matrix proteins; FCS, fetal calf serum; HBsAg, hepatitis B surface antigen; HSC, hepatic stellate cells; IHC, immunohistochemical; IMDM, Iscove's Modified Dulbecco's Medium; LC, liver cirrhosis; MSC, mesenchymal stem cells; PLB, puncture liver biopsy; WHO, World Health Organization; $\alpha$-TNF, tumor necrosis factor alpha.

Received: 02 September 2014; Revised: 18 November 2014; Accepted: 18 November 2014

DOI: $10.14218 / \mathrm{JCTH} .2014 .00027$.

* Correspondence to: Vladimir Maksimovich Tsyrkunov, Department of Infection Diseases Grodno, Grodno State Medical University, Gorkogo street 80, Grodno 230 015, Republic of Belarus. Tel: +375-152-435341, Fax: +375-152432661, E-mail: tvm111@mail.ru tolerated and was not associated with any complications both during and after BMSC transplantation.

( 2014 The Second Affiliated Hospital of Chongqing Medical University. Published by XIA \& HE Publishing Ltd. All rights reserved.

\section{Introduction}

Development of liver cirrhosis (LC) due to chronic hepatitis, including ones of viral etiology, remains a main cause or mortality worldwide. According to the World Health Organization (WHO), LC is responsible for $1.8 \%$ of the total number of fatal outcomes in Europe, accounting for approximately one in 700,000 cases per annum. ${ }^{1}$

Currently, liver transplantation remains the only effective therapeutic strategy available for the treatment of these patients, but due to the lack of donor organs, it is not always a possibility.

Therefore, the development of new therapies, such as cytotherapy, is necessary. By late 2012, there were more than 170 clinical trials registered evaluating the use and efficacy of bone marrow stem cells therapeutically in the pathological progression of liver disease. The results were favorable, ${ }^{2}$ and the total number of such studies has increase to more than 400 by the middle of 2014. Many of these studies examine the therapeutic potential of mesenchymal stem cells (MSC). Given the low immunogenicity of MSCs and their ability to pointedly migrate, MSCs have recently become the focus of intensive research aimed at the application of such cells for stimulating reparation of various tissues, including the liver. Clinical trials examining the use of MSCs demonstrated their high tolerance rate, safety, positive therapeutic effect, and reduction of total mortality rate. ${ }^{3-7}$

Here, we conducted a prospective pilot clinical study to evaluate the effect of autologous bone marrow-derived mesenchymal stem cells (BMSC) implanted into the liver parenchyma during fibrogenesis/fibrolysis and regeneration in the liver tissue of patients with hepatitis $\mathrm{C}$ virus (HCV)related $\mathrm{LC}$.

\section{Methods}

This trial protocol was approved by the Committee for Ethics of "The Republican Research and Practical Center of Pediatric Oncology and Hematology". In total, six patients (three males and three females, mean age of $44.5 \pm 2.7$ years) with 
Table 1. General design scheme of the study

\begin{tabular}{lll}
\hline Visit I & Visit II & Visit III \\
\hline$n=6$ & $n=6$ & $n=6$ \\
PLB & Treatment at the out-patient department & Evaluation of therapeutic results; 6 ${ }^{\text {th }}$ month \\
Intraparenchymal introduction of BMSC & Dynamic evaluation within 5 months & PLB \\
\hline
\end{tabular}

HCV-related LC of Class B and C (after Child-Pugh) were recruited for this study. All patients underwent general clinical and biochemical blood analyses and ultrasound examination of abdominal organs. Also, blood markers of hepatitis viruses (hepatitis B surface antigen (HBsAg), anti-HCV, HCV RNA)) were evaluated and puncture liver biopsy (PLB) was performed. All patients signed informed consent prior to participation in the study. The study design is presented in Table 1.

Patients were followed for up to 6 months after BMSC implantation. At follow-up, clinical assessment and laboratory tests were done and PLB was performed at 6 months after the transplantation.

\section{Preparation the autotransplant of the BMSC}

The autotransplant of the BMSCs was prepared essentially as previously described. ${ }^{1,8}$ One modification to minimize the possibility of contaminating blood cells with viral infection was comprised of a triple wash of the surface of the vial containing adhesive cells $48 \mathrm{~h}$ after beginning of cultivation of mononuclear cells of bone marrow. Mononuclear cells were isolated from bone marrow obtained from patients under anesthesia by puncture in the amount of $60 \mathrm{~mL} 33-45$ days prior to the scheduled infusion of BMSC. It was stored at a concentration of $1-2 \times 10^{6} / \mathrm{mL}$ in vials until further cultivation in a $\mathrm{CO}_{2}$ incubator. BMSCs were developed with several passages in vitro in Iscove's Modified Dulbecco's Medium (IMDM) with $10 \%$ fetal calf serum (FCS) (Sigma, St. Louis, MO, USA), 2 mML-glutamine, and the addition of $10^{-4} \mathrm{M}$ of 2mercaptoethanol in order to reach the required volume (dependent on patient body weight). The cells, removed from the surface of culture vials of the final passage, were washed in physiological solution twice and transferred into $5 \mathrm{~mL}$ of $\mathrm{NaCl}$ for infusion to the patient. Attributes of the BMSCs obtained by this were confirmed by the presence of the surface markers CD105+, CD90+, and CD73+. BMSCs from each passage were evaluated for their sterility.

To evaluate cell viability, the latter were stained with $0.4 \%$ trypan blue. Coefficient of vital capacity of cells (percentage of the total number of counted cells) was computed.

\section{Choice of transplantation technique}

BMSCs ( $5 \mathrm{~mL}$ suspension, $1 \times 10^{6} / \mathrm{kg}$ of body weight, $1 \mathrm{~mL}$ in each of five spots) were intraparenchymally introduced under ultrasound control. Advantages of this technique include its relative safety, BMSC effects upon definite sections of the organ, ability to exclude cell homing outside the hepatic tissue (important for objectivity), and ability to accurately interpret results obtained with morphological study of biopsy materials taken from the treated hepatic area.

\section{Criteria for evaluation of transplantation efficacy rate}

IHC-applied biopsy samples of the liver were fixed in a $10 \%$ neutral formalin solution and covered with paraffin using a routine technique. Samples were probed with commercial antibodies for CD34+ and $\alpha$-SMA (Dako, Denmark).

$0.05 \mathrm{M}$ Tris buffer $(\mathrm{pH} 7,4)$ (Serva) with saponin $(0.01 \%)$ was used as a base fluid. Sections were deparaffinized in xylol, rehydrated in descending concentrations of the alcohol battery, and then washed in distilled water. Antigen unmasking was performed in a microwave oven for 7 minutes at $800 \mathrm{~W}$, and then 15 minutes at $400 \mathrm{~W}$, buffer solutions pH 6.0 and 9.0 were used. Endogenous peroxidase was blocked by $3 \%$ $\mathrm{H}_{2} \mathrm{O}_{2}$ for 30 minutes. A solution of $1 \%$ FCS was applied for 30 minutes to block nonspecific binding of antibodies onto the surface of a slice preparations. Incubation with the primary antibody was performed for 30 minutes. EnVision (Dako, Denmark) was used as an imaging system, diaminobenzidine (Dako, Denmark) at a concentration of $1 \mathrm{mg} / \mathrm{mL}$ with the addition of $\mathrm{H}_{2} \mathrm{O}_{2}(0.02 \%$ solution) was used as a chromogen. Samples were placed in xylol for 1 minute, then stained with Mayer's hematoxylin (Sigma, USA).

For a morphometric study the micropreparations were photographed in five and/or six visual fields (the lens of 40 ), and in 10 visual fields (the lens of 100 ) at a resolution of $1798 \times 1438$ pixels by a microscope digital camera Leica. The area of the visual fields was $298.47 * 238.71=71,247.77 \mu \mathrm{m}^{2}$ (increase by $\times 40$ ) and $113.53 * 98.29=11,158.86 \mu \mathrm{m}^{2}$ (increase by $\times 100$ ), respectively.

The prevalence of fibrosis (CD34, $\alpha$-SMA) was assessed by semiquantitative method: 1 point meant slightly pronounced (immunoreactiveness of cells is in the single sinusoidal lobes); 2 points meant moderately pronounced (immunoreactiveness of cells is about half of sinusoidal lobes); 3 points meant strongly pronounced (immunoreactiveness of cells is most sinusoidal lobes).

Biopsy materials were visualized at the ultrastructural level using electronic microscopy (EM). EM studies were performed on liver biopsy samples sequentially fixed in $1 \%$ osmium tetroxide and $2.5 \%$ glutaraldehyde (both made in $0.1 \mathrm{M}$ Millonig). ${ }^{9}$ Ultrathin $\left(35 \times 10^{-9} \mathrm{~m}\right)$ sections were contrasted with $2 \%$ uranyl acetate in $50 \%$ methanol $^{10}$ and $\mathrm{Pb}$ citrate (as described in Reynolds). ${ }^{11}$ EM preparations were studied under a JEM-1011 (JEOL Ltd., Tokyo, Japan) electronic microscope at 10,000-40,000 zoom with an accelerating voltage of $80 \mathrm{~kW}$. The images were photographed with the Olympus MegaView III (Shinjuku, Japan) digital camera.

\section{Statistics}

Descriptive statistics are shown as mean \pm SD and median values with interquartile range. Unpaired Student t-tests. Variables with $\mathrm{p} 0.05$ were considered statistically signifcant. Statistical analysis was performed using STATISTICA 6 software.

\section{Results}

We evaluated the morphological features of liver biopsy samples to determine degree of activity and stage of 
Lukashyk S.P. et al: Mesenchymal BMSCs transplantation in liver

Table 2. Clinical data of all patients before and after MSCs injection

\begin{tabular}{llll}
\hline Features & $\begin{array}{l}\text { Before } \\
\text { transplantation }\end{array}$ & $\begin{array}{l}1 \text { month after } \\
\text { transplantation }\end{array}$ & $\begin{array}{l}6 \text { month after } \\
\text { transplantation }\end{array}$ \\
\hline $\begin{array}{l}\text { Gender } \\
\text {. male }\end{array}$ & $3(50 \%)$ & $3(50 \%)$ & $3(50 \%)$ \\
. female & $3(50 \%)$ & $3(50 \%)$ & $3(50 \%)$ \\
$\begin{array}{l}\text { General weakness } \\
\text { p presence }\end{array}$ & $6(100 \%)$ & $0(0 \%)$ & $0(0 \%)$ \\
. absence & $0(0 \%)$ & $6(100 \%)$ & $6(100 \%)$ \\
$\begin{array}{l}\text { Jaundice } \\
\text { presence }\end{array}$ & & $2(33 \%)$ & $2(33 \%)$ \\
absence & $4(67 \%)$ & $4(67 \%)$ & $4(67 \%)$ \\
\hline
\end{tabular}

chronization. In addition, we estimated the activation rate of microblasts by measuring the expression of alpha-smooth muscle actin ( $\alpha$-SMA) and CD34+ (a measure of the phenomenon of "capillarization" of sinusoids) using immunohistochemistry (IHC). Efficacy rate was ascertained at 6 months after transplantation. In order to evaluate the effectiveness of the treatment, dynamic of clinical (complaints and objective status of patients) and laboratory (levels of urea, creatinine, albumin, cholesterol, bilirubin, alanine aminotransferase (ALT), aspartate aminotransferase (AST)) tests were studied.

All patients enrolled in the study had LC with no ascites, peripheral edema, or bleeding signs. Splenomegaly was registered in all patients. Ultrasound examination of the hepatobiliary system confirmed the presence of cirrhosis of the liver and intrahepatic portal hypertension. In four patients, there was slight jaundice. Two patients had a history of ascites and encephalopathy. All patients had normal levels of urea, creatinine, albumin, and cholesterol in blood tests. Clinical data for all patients are presented in Table 2.

One month after BMSC transplantation, the general condition of patients improved. After 1 and 6 months, jaundice was absent in four (67\%) patients. After 6 months, functional hepatic indices were improved, i.e. decrease of ALT and AST activity and bilirubin level. However, there was no statistically significant difference in these levels $(P>0.05)$. Morphological studies of liver biopsy samples before therapy and 6 months after transplantation revealed activation of fibrolysis and regeneration of hepatocytes (Fig. 1-4, a case of LC in patient D).

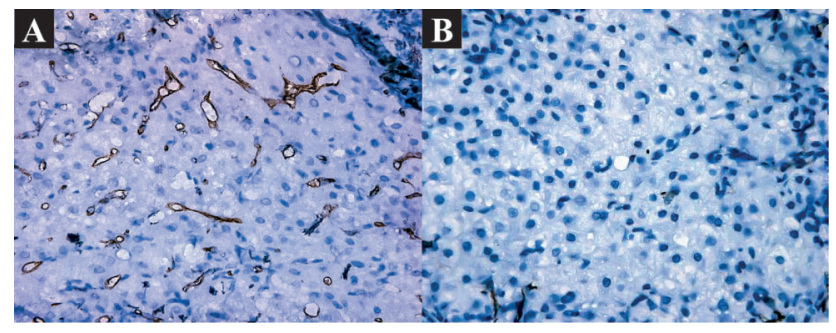

Fig. 1. Capillarization of sinusoids. (A) Before BMSC transplantation: pronounced capillarization of sinusoids. IHC: CD34+. $\times 400$. (B) 6 months after BMSC transplantation: slightly pronounced capillarization of sinusoids. IHC: CD34+. $\times 400$.
None of the patients demonstrated any complications due to BMSC transplantation or during the follow-up period.

\section{Discussion}

This study included patients with HCV-related liver cirrhosis and intrahepatic portal hypertension. Liver disease in these types of patients is progressive and may not be treated with interferon because of the risk for decompensation.

Clinical trials with BMSCs have demonstrated improvement of general well-being in patients with decompensated liver cirrhosis. ${ }^{5,26,27}$ However, the question remained, what is happening in the liver to improve its function? Therefore, we investigated mechanisms underlying how autologous BMSCs can help resolve existing fibrosis. We utilized not only clinical and laboratory evaluation methods, but also comprehensively assessed the morphology of liver biopsies (using light and electron microscopy, IHC). Autologous MSCs from patient bone marrow were selected as the graft material. Transplantation directly into the liver tissue was chosen because of the high probability of graft exposure.

We found at 1 and 6 months after transplantation a number of positive clinical and laboratory trends: improvement in the overall health of patients (no complaints), decline in bilirubin, ALT, and AST in the biochemical analysis of blood. However, the difference in these was not statistically significant. We suspect that these improvements were due to structural changes in the liver tissue. Previously, we had reported similar structural changes in patients with chronic hepatitis due to $\mathrm{HCV}^{28}$

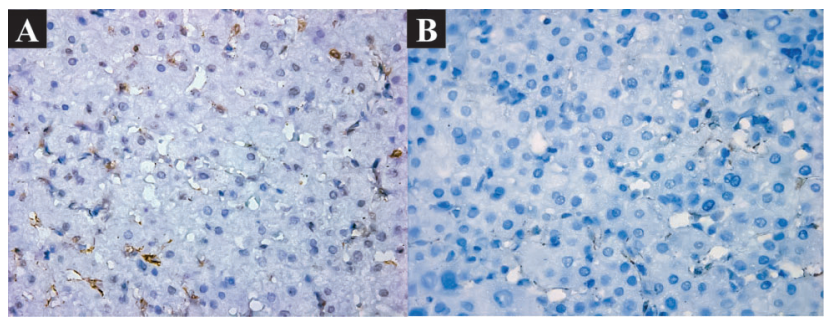

Fig. 2. Activation of miofibroblasts. (A) Before BMSC transplantation: moderately pronounced. IHC: $\alpha$-SMA. $\times 400$. (B) 6 months after BMSC transplantation: slightly pronounced: IHC: $\alpha$-SMA. $\times 400$ 


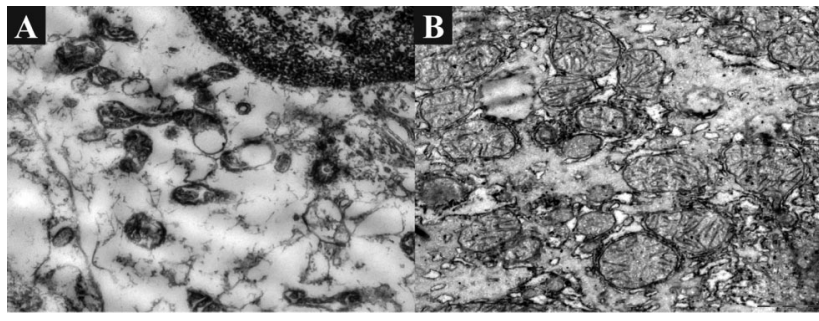

Fig. 3. Condition of mitochondria of hepatocytes. (A) Before transplantation of BMSC: Mitochondria are atypical in shape, have reduced cristae, condensed matrix, desquamation of outer membrane, and formation of blisters. $\times 10000$. (B) 6 months after BMSC transplantation: Mitochondria are numerous in number, hypertrophied, with diffuse localization, polymorphism, divisible, and with multiple cristae. $\times 10000$.

We comprehensively evaluated liver biopsies with electron microscopy and IHC, and found that MSCs influenced both fibrolysis and regeneration. The electron microscopy data demonstrated that LC patients administered BMSCs exhibited intracellular regeneration processes. Morphological features determine recovery in the function of hepatocytes, which was verified by improvement of laboratory parameters. We believe that using a "from structure to function" approach has many advantages for the evaluation of chronic liver disease after transplantation of BMSC. These include the objectification of results, the ability to identify the logical relationship occurring in parenchymal and non-parenchymal compartments, and the ability to explain many pathological mechanisms that mediate the observed clinical signs in patients with liver cirrhosis.

Persistent inflammation and fibrogenesis in liver tissue are dynamic processes. Regeneration and fibrolysis follow the elimination of inflammation and the reduction of hepatic stellate cell (HSC) activation. These events lead to the degradation of newly formed EMPs, causing regression of fibrosis and regeneration processes in hepatocytes.

Previously, it had been shown that BMSCs lead to reorganization of the parenchymal and nonparenchymal liver compartments, remodeling of the ECM, and limiting the progression of liver fibrosis. ${ }^{18,19}$ Recently, it was demonstrated that BMSCs interact with $\mathrm{HSC}$, where cases of viral damage were the main source of fibrillar collagens and other EMPs of fibrous tissues. Experimental studies have shown that BMSCs caused a multiple synergic effect on the condition and functional activity of HSC, i.e. to inhibit activated cells, to

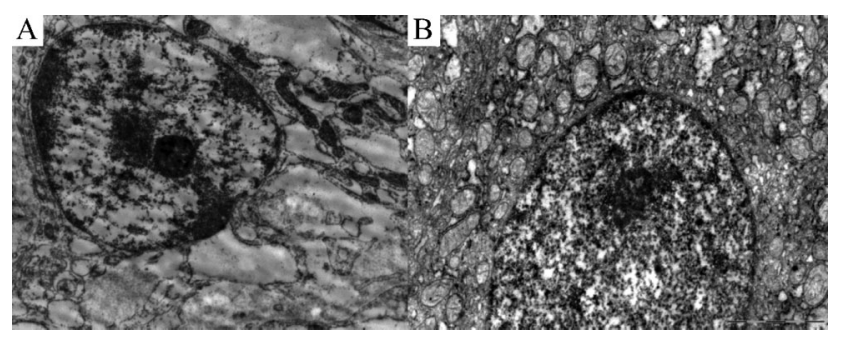

Fig. 4. Nuclei of hepatocytes. (A) Before transplantation. Nucleus of hepatocyte is rounded. Margination of chromatin. Compact nucleolus with predominantly fibrillar component. Hydropic degeneration in cytoplasm of a hepatocyte. $\times 10000$. (B) 6 months after BMSC transplantation: Nucleus of hepatocyte is oval. Nucleolus is predominantly with granular component. $\times 15000$. prevent their new activation, and/or to modulate the effects of HSC. ${ }^{2,20}$ Mechanistically, this is due to the paracrine effect of BMSCs via interleukin-10 (IL-10), tumor necrosis factor alpha ( $\alpha$-TNF), and hepatocytic growth factor. It was also established that activated HSCs themselves could secrete IL6 , thereby inducing secretion of IL-10 by mesenchymal cells and favoring dynamic interaction of cells within the established microenvironment. ${ }^{21}$ Multiple researchers have reported on the ability of BMSCs to prevent the shift of HSCs from the dormancy stage to the active one ("preventive" effect of BMSCs). Consistent with this, in vitro studies (co-culture of BMSCs and HSCs) have found that the number of HSCs at the G0 stage of the cell cycle was increased while that in the S-stage tended to decrease. ${ }^{22}$ At the same time, reducing inflammation severity and the number of HSCs can aid in the regeneration of hepatocytes.

Autologous cells of stromal origin were used in our study because BMSCs, which belong to the mesodermal embryonic blastema, are capable of differentiating into cells of tissues originating from the endodermal (liver, pancreas, urinary tracts) embryonic blastemae. ${ }^{12-14}$ One of the challenges of a vast application of BMSC was overcome by the fact that those cellular elements could be easily isolated from bone marrow and their number could be easily enlarged under rather uncomplicated cultivation conditions. Thus, upon cultivation of BMSCs in medium containing specific stimulators of differentiation of hepatic cells or upon their joined cultivation with hepatocytes (such markers of hepatocytes as c/EBP $\beta$ and HNF $4 \alpha$ transcription factors), the cells began to acquire a polygonal shape and the ability to secrete albumin and $\alpha$ fetoprotein. ${ }^{15-17}$

Transplanted BMSCs can avoid immune control, and they demonstrate immune-modulating and antiinflammatory activity via the paracrine effect of BMSCs and the intercellular interaction between BMSCs and immune cells. 6,7 However, the mechanism underlying the effect of BMSCs on liver regeneration and how to apply these aspects to the treatment of LC require additional verification. Although controversial, there is some evidence suggesting that BMSCs in hepatic tissues may acquire a myofibroblast phenotype and secrete molecules displaying profibrogenic activity. ${ }^{23-25}$

From our perspective, it is important to use autologous BMSCs because it has several important advantages. This approach avoids certain ethical constraints, eliminates the need for additional prescribing of immunosuppressant after transplantation. The best responses from BMSC transplantation may be achieved in those patients who previously suppressed virus replication and were at an earlier stage of disease progression (chronic hepatitis, but not liver cirrhosis).

Study limitations: There are a number of limitations of our study. These include a small number of patients, short duration of the follow-up period, and a single procedure for BMSC transplant.

\section{Conclusions}

Intraparenchymal transplantation of autologous BMSC improved functional condition of the liver, stimulated reparative processes in hepatocytes, and decreased EMP count in hepatic tissues of patients with LC. As shown in our study, this transplantation methodology was well tolerated and was not associated with any complications both during and after the BMSC transplant procedure. 


\section{Conflict of interest}

None

\section{Author contributions}

Study design (SPL, VMT, OVA, ONR, YII), mycroscopy conducting (RIK), graft transplantation and puncture liver biopsy performing (ATS), data analysis (SPL, VMT, OVA), manuscript writing (SPL, VMT), critical revision (OVA, SPL, VMTs, YII, ONR, ATS, RIK).

\section{References}

[1] Zatonski WA, Sulkowska U, Manczuk M, Rehm J, Boffetta P, Lowenfels AB et al. Liver cirrhosis mortality in Europe, with special attention to Central and Eastern Europe. Eur Addict Res 2010;16:193-201. doi: 10.1159/ 000317248 .

[2] Forbes SJ, Newsome PN. New horizons for stem cell therapy in liver disease. J Hepatol 2012;56:496-499. doi: 10.1016/j.jhep.2011.06.022.

[3] Friedman SL. Evolving challenges in hepatic fibrosis. Nat Rev Gastroenterol Hepatol 2010;7:425-436. doi: 10.1038/nrgastro.2010.97.

[4] Mohamadnejad M, Alimoghaddam K, Mohyeddin-Bonab M, Bagheri M, Bashtar $\mathrm{M}$, Ghanaati $\mathrm{H}$, et al. Phase 1 trial of autologous bone marrow mesenchymal stem cell transplantation in patients with decompensated liver cirrhosis. Arch Iran Med 2007; 10:459-466.

[5] Uccelli A, Moretta L, Pistoia V. Mesenchymal stem cells in health and disease. Nat Rev Immunol 2008;8:726-736. doi: 10.1038/nri2395.

[6] Zhang L, Theise N, Chua M, Reid LM. The stem cell niche of human livers: symmetry between development and regeneration. Hepatol 2008;48:15981607. doi: 10.1002/hep.22516.

[7] Zhang $\mathrm{Z}$, Lin $\mathrm{H}$, Shi $\mathrm{M}, \mathrm{Xu} \mathrm{R}, \mathrm{Fu} J$, Lv J, et al. Human umbilical cord mesenchymal stem cells improve liver function and ascites in decompensated liver cirrhosis patients. J Gastroenterol Hepatol 2012;27(Suppl 2): 112-120. doi: 10.1111/j.1440-1746.2011.07024.x

[8] Isaikina Ya I, Aleinikova O.V. Sposob ekspansii mezenkhimalnykh stvolovykh kletok (The way of expansion of mesenchymal stem cells). Afitsiyny biul. / Nats. tsentr intellectual. ulasnastsi 2009;1:93.

[9] Millonig GA. Advantages of a phosphate buffer for osmiumtetroxide solutions in fixation. J Appl Physics 1961;32:1637-1643.

[10] Watson ML. Staining of tissue sections for electron microscopy with heavy metals. J Biophys Biochem Cyt 1958;4:475-478. doi: 10.1083/jcb.4.4.475.

[11] Reynolds ES. The use of lead citrate at high $\mathrm{pH}$ as an electron opaque stain in electron microscopy. J Cell Biol 1963;17:208-212. doi: 10.1083/ jcb.17.1.208.

[12] Vladimirskaya YeB. Mezenkhimalniye stvoloviye kletki (MSK) v kletochnoy terapii (Mesenchymal stem cells (MSC) in cellular therapy). Onkogematol 2007;1:4-16.

[13] Makino S, Fukuda K, Miyoshi S, Konishi F, Kodama H, Pan J, et al. Cardiomyocytes can be generated from marrow stromal cells in vitro. J Clin Invest 1999;103:697-705. doi: 10.1172/JCI5298.
[14] Beltrami AP, Urbanek $K$, Kajstura J, Yan SM, Finato N, Bussani $R$, et al. Evidence that human cardiac myocytes divide after myocardial infarction. N Engl J Med 2001;344:1750-1757. doi: 10.1056/NEJM200106073442303.

[15] Talens-Visconti R, Bonora A, Jover R, Mirabet V, Carbonell F, Castell JV, et al. Hepatogenic differentiation of human mesenchymal stem cells from adipose tissue in comparison with bone marrow mesenchymal stem cells. World J Gastroenterol 2006;12:5834-5845. doi: 10.3748/wjg.v12.i36.5834.

[16] Luk JM, Wang PP, Lee CK, Wang JH, Fan ST. Hepatic potential of bone marrow stromal cells: development of in vitro co-culture and intra-portal transplantation models. J Immunol Methods 2005;305:39-47. doi: 10.1016/ j.jim.2005.07.006.

[17] Seo MJ, Suh SY, Bae YC, Jung JS. Differentiation of human adipose stromal cells into hepatic lineage in vitro and in vivo. Biochem Biophys Res Commun 2005;328:258-264. doi: 10.1016/j.bbrc.2004.12.158.

[18] Abdel Aziz MTA, Atta HM, Mahfouz S, Fouad HH, Roshdy NK, Ahmed HH, et al. Therapeutic potential of bone marrow-derived mesenchymal stem cells on experimental liver fibrosis. Clin Biochem 2007;40:893-899. doi: 10.1016/ j.clinbiochem.2007.04.017.

[19] Fang B, Shi M, Liao L, Yang S, Liu Y, Zhao RC. Systemic infusion of FLK1 mesenchymal stem cells ameliorate carbon tetrachloride-induced liver fibrosis in mice. Transplant 2004;78:83-88. doi: 10.1097/01.TP.0000128326.95294.14.

[20] Friedman SL. Hepatic stellate cells: protean, multifunctional, and enigmatic cells of the liver. Physiol Rev 2008;88:125-172. doi: 10.1152/physrev. 00013.2007.

[21] Parekkadan B, van Poll D, Megeed Z, Kobayashi N, Tilles AW, Berthiaume F, et al. Immunomodulation of activated hepatic stellate cells by mesenchymal stem cells. Biochem Biophys Res Commun 2007;363:247-252. doi: 10.1016/j.bbrc.2007.05.150.

[22] Zhao DC, Lei JX, Chen R, Yu WH, Zhang XM, Li SN, et al. Bone marrowderived mesenchymal stem cells protect against experimental liver fibrosis in rat. World J Gastroentrol 2005;11:3431-3440.

[23] Carvalho AB, Quintannilha LF, Dias JV, Paredes BD, Mannheimer EG, Carvalho FG, et al. Bone marrow multipotent mesenchymal stem cells do not reduce fibrosis or improve function in a rat model of severe chronic liver injury. Stem Cells 2008;26:1307-1314. doi: 10.1634/stemcells.2007-0941.

[24] Di Bonzo LV, Ferrero I, Cravanzola C, Mareschi K, Rustichell D, Novo E, et al Human mesenchymal stem cells as a two-edged sword in hepatic regenerative medicine: engraftment and hepatocyte differentiation versus profibrogenic potential. Gut 2008;57:223-231. doi: 10.1136/gut.2006.111617.

[25] Russo FP, Alison MR, Bigger BW, Amofah E, Florou A, Amin F, et al. The bone marrow functionally contributes to liver fibrosis. Gastroenterol 2006;130: 1807-1821. doi: 10.1053/j.gastro.2006.01.036.

[26] Kharaziha P, Hellstrom PM, Noorinayer B, Farzaneh F, Aghajani K, Jafari F, et al. Improvement of liver function in liver cirrhosis patients after autologous mesenchymal stem cell injection: a phase I-II clinical trial. Eur J Gastroenterol Hepatol 2009;21:1199-1205. doi: 10.1097/MEG.0b013e32832a1f6c.

[27] Terai S, Ishikawa T, Omori K, Aoyama K, Marumoto Y, Urata Y, et al. Improved liver function in patients with liver cirrhosis after autologous bone marrow cell infusion therapy. Stem Cells 2006;24:2292-2298. doi: 10.1634/ stemcells.2005-0542.

[28] Lukashyk SP, Tsyrkunov VM, Andreev VP, Kravchuk RI, Abakarova VA. Patogeneticheskaya rol populiatsiyi zvezdchatykh kletok Ito i kletochnykh koopertsiy $v$ formirovanii fibroza pri khronicheskom gepatite $C$ (Pathogenetic role of population of Ito stellate cells and cellular cooperation in formation of fibrosis in chronic $C$ hepatitis). Infektsionniye bolezni 2010;8:7-12. 